\title{
Management of Blunt Hepatic Trauma
}

\author{
Takatoshi SHIMOYAMA, Rhoji TAKAHIRA, Teruhisa SHIMIZU \\ Hiroshi ISHIKAWA, Kohsei MIYASHITA, Naoki KAWAZOE \\ Takayuki NAKAZAKI, Hiroyuki YAMAGUCHI, Nobuko KUROSAKI \\ Hiroyuki KUSANO, Tohru NAKAGOE, Tatsuo HIRANO \\ Tsutomu SAKAI, Toshio MIURA, and Masao TOMITA
}

First Department of Surgery, Nagasaki University, School of Medicine,
Nagasaki, Japan.

Received for publication, June 25, 1990

\begin{abstract}
One hundred and twelve consecutive cases with blunt hepatic trauma between January 1, 1965 and December 31, 1988 at the First Dpartment of Surgery, Nagasaki University were reviewed. Fifty-seven patients had minor injuries, 33 moderate injuries and 22 severe injuries. Sixty-five patients (58\%) sustained also one of more associated injuries. Out of 43 patients over the last ten years 30 were diagnosed by US or CT. Eighty-eight patients (78.3\%) underwent laparotomy; laparotomy and drainage alone in 13 , suture and packs in 57 , debridement and minor liver resection in 11 and right lobectomy in 9. The results of treated patients were assessed according to the grading of liver injury and assocated injury. The overall mortality was $13.4 \%$ (15 of 112). True liver-related mortality due to hemorrhage was $26.7 \%$ ( 4 of 5), and the other 11 patients who died were due to refractory shock and the development of multiple organ failure (MOF). Twenty-one patients were conservatively managed with only one death, and the other 20 survivors had no complications and healed completely from 6 to 12 months after trauma. Although lobectomy or resectional debridement are advocated as an operative procedure for massive injury, a conservative management for mild or moderate ruptures is still recommended as far as possible.
\end{abstract}

\section{INTRODUCTION}

Blunt hepatic trauma is the most common event in abdominal trauma which is difficult to rescue without proper management. Most series dealing with blunt hepatic trauma have reported the multiple organ injury associated with blunt hepatic trauma at about $59 \%$ of patients and the mortality at $20-60 \% \%^{1,6 \sim 10)}$. On the other hand, over the last ten years, the use of both significantly advanced Ultrasonography (US) and Computed tomography (CT) have rapidly come into widespread $u^{2} e^{2}$. This has led to the current advance in the diagnosis and management with traumatized patients. The purpose of this paper is to review our experience with blunt hepatic trauma, with a view to the evaluation of current methods of diagnosis and treatment.

\section{CLINICAL MATERIAL}

The present study consists of an analysis of 112 consecutive patients who sustained blunt hepatic trauma and were admitted alive to the First Department of Surgery, Nagasaki University Hospital, during the period from January 
1, 1965 to December 31, 1988. The current series of liver injury represented a sequel to the previous series with 60 patients covering the period from 1965 to 1977. Data from the previous series were presented to analyze some changing concepts, in comparison with 52 patients in the recent series from 1978 to 1988, in which most of the patients were diagnosed by US or CT.

Age \& Sex: There are 93 males and 19 females. Their ages ranged from newborn to 74 years. Table 1 shows an age and sex distribution of 60 patients in previous sereis from 1965 to 1977 , comparing 52 patients in recent series from 1978 to 1988. A similar distribution was found in each sereies.

Cause of Injury: The frequent cause of injury was a traffic accident including pedestrians struck by the automobile. Approximately $43 \%$ of the patients were below 20 years of age (Table 2).

Associate Injury: The combined damages with other organs were shown in Table 3. There were few cases with localized liver damage. Sixty-five patients $(58 \%)$ received one or more associated injuries. Associated injuries were frequently observed such as rib fractures, extremity fracture, intra-abdominal parenchymatous organs as well as lung injuries.

Mode of Liver Injury: The mode of liver injury
Table 3. Associated Injuries with Blunt Hepatic Trauma

\begin{tabular}{lcc}
\hline & $\begin{array}{c}\text { No. of } \\
\text { patients }\end{array}$ & $\%$ \\
\hline 1. Chest & 34 & 33.0 \\
rib & 21 & \\
hemo-pneumothorax & 10 & \\
diaphragm & 3 & \\
2. Abdomen & 36 & 35.0 \\
kidney & 12 & \\
intestine & 10 & \\
pancreas & 7 & \\
spleen & 7 & \\
3. Others & 28 & 27.2 \\
head \& face & 11 & \\
supine & 4 & \\
extremity & 9 & \\
pelvis & 4 & \\
\hline
\end{tabular}

according to Moynihan's classification3) were lacerations in 84, subcapsular ruptures in 24 and central ruptures in 4 . Although the incidence of the lacerations was similar in each period, there has been a concomitant increase in the percentage of subcapsular rupture from $11.7 \%$ in the previous series to $32.7 \%$ in the recent series. This reflects a recent advantage of diagnostic imaging procedures.

The site of damage in the liver was analyzed in terms of the surgical segments constructed

Table 1. Age and Sex Distribution of Blunt Hepatic Trauma

\begin{tabular}{lcrrrrrrrr}
\hline Age & \multirow{2}{*}{ Newborn } & $\sim 10$ & $10 \sim$ & $20 \sim$ & $30 \sim$ & $40 \sim$ & $50 \sim$ & $60 \sim$ & Total \\
\hline Period & & 16 & 10 & 8 & 10 & 9 & 2 & 0 & 60 \\
$1965-1977$ & 4 & 7 & 12 & 5 & 11 & 9 & 5 & 3 & 52 \\
\hline $1978-$ & 1 & 23 & 22 & 13 & 21 & 18 & 7 & 3 & 112 \\
\hline Total & 5 & 23 &
\end{tabular}

Male : 93 Female : 19

Table 2. Type of Inflicting Agent of Blunt Hepatic Trauma

\begin{tabular}{|c|c|c|c|}
\hline & 1965-1977 & $1978^{-}$ & Total \\
\hline & No. of patients & No. of patients & $10 t a 1$ \\
\hline Traffic accident & 30 & 42 & 72 \\
\hline External compression & 3 & 4 & 7 \\
\hline Fell down from high place & 13 & 2 & 15 \\
\hline Fighting & 7 & 3 & 10 \\
\hline Newborn & 4 & 1 & 5 \\
\hline Others & 3 & 0 & 3 \\
\hline Total & 60 & 52 & 112 \\
\hline
\end{tabular}


Table 4. Grade of Blunt Hepatic Trauma

\begin{tabular}{ccccc}
\hline \multirow{2}{*}{ Grade } & $1965-1977$ & & 1978 & Total \\
\cline { 2 - 2 } & No. of patients & No. of patients & \\
\hline I (Minor) & $35(58.3)$ & & $22(42.3)$ & $57(50.9)$ \\
II (Moderate) & $13(21.7)$ & & $20(38.5)$ & $33(29.5)$ \\
III (Severe) & $12(20)$ & $10(19.2)$ & $22(19.6)$ \\
\hline Total & $60(100 \%)$ & $52(100 \%)$ & $112(100 \%)$ \\
\hline
\end{tabular}

Grede I: Small lacerations of liver parenchyma with/without ruptures of liver capsule.

Grede II : Moderate injuries with significant amounts of exposed liver parenchyma in two segments, but without main vessels injuries.

Grede III : Major hepatic injuries with tissue disruption, devitalization, massive hemorrhage and bile leak from main vessels injuries.

by Cantlie line. There were 86 right lobe, 18 left lobe, 7 bilateral lobes and 1 hilum. The right lobe was more susceptible to injury.

Grade of Liver Injury: We classified the injured liver into 3 types according to the severity of liver injury ${ }^{4,10}$ ) (Table 4 Fig. 1, 2). The mortality from blunt hepatic trauma is correlated well with the grade of this classification.

\section{RESULTS}

Our managements for 112 patients with blunt hepatic trauma is summarized in Table 5-7. In the previous series, 58 patients (96.7\%) underwent laparotomy with various techniques, whereas 19 patients (36.5\%) were conservatively managed in the recent series.

Grade 1 (Minor injury): Eight patients who were hemodynamically stable and lacked obvious clinical indications for laparotomy were conservatively managed. Simple laparotomy and abdominal drainage alone were performed in 11 patients, because liver wound had stopped bleeding at the time of laparotomy. Two patients died from reflactory shock and respiratory failure.

Table 5. Management of Minor Injuries (grade I) in Blunt Hepatic Trauma

\begin{tabular}{ccccc}
\hline \multirow{2}{*}{ Management } & $1965-1977$ & & $1978-$ & \multirow{2}{*}{ Total } \\
& No. of patients & & No. of patients & \\
\hline Conservative & 2 & & 11 & 13 \\
Exploration \& Drainage & 7 & & 4 & 11 \\
Suture \& Packing & $35(1)$ & & $7(1)$ & $33(2)$ \\
Total & $97.1 \%$ & & $17(1)$ & $57(2)$ \\
\hline Survivors & & $94.1 \%$ & $96.5 \%$ \\
\hline
\end{tabular}

Table 6. Management of Moderate Injuries (grade II) in Blunt Hepatic Trauma

\begin{tabular}{cccccc}
\hline \multirow{2}{*}{ Management } & $1965^{-1977}$ & & $1978^{-}$ & \multirow{2}{*}{ Total } \\
\cline { 2 - 3 } & No. of patients & & No. of patients & \\
Conservative & 0 & 7 & $11(1)$ & 7 \\
Suture \& Packing & $12(5)$ & & 1 & $22(6)$ \\
Debridement & 1 & & & 2 \\
Partial hepatectomy & 0 & & 1 & 1 \\
Total & $61.5 \%$ & & $95 \%$ & $33(6)$ \\
\hline Survivors & & & $($ ) $:$ No. of Death
\end{tabular}


Grade II (Moderate injury): In the recent series seven patients were selected for nonoperative management because of the lack of clinical indications for laparotomy and the findings of liver injury on abdominal CT and/or ultrasound. Of these patients, 5 had a subcapsular rupture, and the other 2 had a small laceration of capsule with moderately parenchymal injury of the right lobe. All patients recovered from their liver injuries without sequelae.

Twenty-three patients with the usual type of lacerations, which were rather extensive and continued to bleed were treated by liver suture and/or packs, with 6 deaths. In the recent series, we used the viable omental packs for deep fractures of the liver on 7 patients with good results.

Grade III (Severe injury): One patient with central parenchymal rupture was conservatively managed, because of no evidence of intraabdominal bleeding. On admission, he was in a deep unconscious state and died from subsequent MOF 11 days after trauma. Two patients with exploration only died on the operating table due to uncontrollable bleeding by bursting injury. Two patients had debridement for devitalized tissues, and 15 patients required hepatic resection to control the bleeding.

Nine patients underwent right hepatic lobectomy for major injury. Three of them were sent to our hospital with temporary gauze packs by local hospitals. Two patients with subcapsular rupture required right lobectomy because of a rapid increase of subcapsular hematoma on admission. Two patients died from reflactory shock and multiple organ failure (MOF) and the remaining 7 patients survived. A followed-up scintigram after right lobectomy revealed that residual liver rapidly increased in size during postoperative weeks and regeneration was complete within 6 months after hepatectomy. One patient with chronic hepatitis died because of rupture of esophageal varices 8 years after right

Table 7. Management of Severe Injuries (grade III) in Blunt Hepatic Trauma

\begin{tabular}{|c|c|c|c|}
\hline \multirow{2}{*}{ Management } & $1965-1977$ & 1978- & \multirow{2}{*}{ Total } \\
\hline & No. of patients & No. of patients & \\
\hline Conservative & 0 & $1(1)$ & $1(1)$ \\
\hline Exploration only & $2(2)$ & 0 & $2(2)$ \\
\hline Suture & 0 & $2(1)$ & $2(1)$ \\
\hline Debridement & 0 & 2 & 2 \\
\hline Partial hepatectomy & 1 & 0 & 1 \\
\hline Left lateral segmentectomy & $2(1)$ & 3 & $5(1)$ \\
\hline Right lobectmy & $7(1)$ & $1(1)$ & $9(2)$ \\
\hline Total & $13(4)$ & $9(3)$ & $22(7)$ \\
\hline Survivors & $69.2 \%$ & $66.7 \%$ & $68.2 \%$ \\
\hline
\end{tabular}

Table 8. Analysis of Martality from Blunt Hepatic Trauma

\begin{tabular}{|c|c|c|c|}
\hline & $1965-1977$ & $1978-$ & Total \\
\hline & No. of patients & No. of patients & total \\
\hline \multicolumn{4}{|l|}{ I. Haemorrhagic Shock } \\
\hline Active and/or rebleeding & 4 & 0 & 4 \\
\hline Irreversible shock & $2(2)$ & $2(1)$ & $4(3)$ \\
\hline \multicolumn{4}{|l|}{ II. Multiple Organ Failure } \\
\hline Renal failure $\cdot$ MOF & $1(1)$ & $3(2)$ & $4(3)$ \\
\hline Peritonitis $\cdot \mathrm{MOF}$ & $2(1)$ & 0 & $2(1)$ \\
\hline Respiratory · MOF & $1(1)$ & 0 & $1(1)$ \\
\hline Total & $10(5)$ & $5(3)$ & $15(8)$ \\
\hline
\end{tabular}


lobectomy.

Morbidity and Mortality: The common complications after operations were hepatitis, hemopneumothorax, postoperative pleurisy and reflactory shock. Complications that resulted in death were circulatory collapse, biliary peritonitis and renal failure, which develops disseminated intravascular coagulation (DIC) and MOF (Table 8). The overall mortality was $13.4 \%$.

\section{DISCUSSION}

The cases of one hundred and twelve patients sustaing blunt hepatic trauma were reviewed. In the previous series, only available diagnostic options for liver injury were exploratory laparotomy based on abdominal taps or peritoneal lavage for the presence of intraperitoneal bleeding and liver function. These methods were most accurate means to detect intraabdominal injury after blunt trauma, but they do not evaluate the retroperitoneal bleeding or the potential source of bleeding. Recently, the advanced diagnostic techniques such as US or CT made it possible to evaluate the injuries to the liver or to the other organs ${ }^{2,5)}$. Raval and Lamki reported that $\mathrm{CT}$ was the single best imaging test with fewer false-negative and false-positive results in their prospective study comparing CT, US and scintigraphy in abdominal trauma ${ }^{2)}$. In our recent series, approximately $85 \%$ were diagnosed by US or CT.

Ninety-one patients underwent laparotomy and the other 21 patients were conservatively managed. The indication for conservative management of blunt hepatic trauma was previously reported ${ }^{10)}$, i.e., 1) hemodynamically stable and/or stabilized by transfusion, 2) no other significant intra-abdominal injuries, 3) minimal hemoperitoneum, 4) subcapsular rupture or transcapsular rupture with grade I or II without active bleeding, and 5) absence of devitalized tissue. However, for these patients, diagnostic imaging procedures as well as physical examination should be frequently repeated to determine any deterioration in the clinical status ${ }^{10 \sim 13)}$.

On the other hand, for the treatment of blunt hepatic trauma, the selection of an indication of surgery is important for surgeons. Major indications for abdominal exploration following blunt hepatic trauma include the following: 1) pneumoperitoneum 2) continuing hemorrhage and shock 3) persistent unexplained abdominal pain and significant peritoneal irritation, and 4) increasing abdominal distension. Either CT or US can then be utilized to detect the etiology of the changing clinical states.

The surgical procedure of a patient with blunt hepatic trauma depends on the type of injured wounds discovered at operation. Minor lacerations that have stopped bleeding may not require repair, $12.1 \%$ of our patients had bleeding stopped at laparotomy, and were controlled by simple suture or drainage alone. The use of hemostatic agents like Avitene, oxycel, gelfoam or liquid thrombin for minor injury were sufficient to control bleeding. However, for most of these patients, the recent improvement in radiological evaluation and diagnosis of liver injury has led to the successful non-operative management.

Moderate lacerations without main vessels injuries required suture and packs against active bleeding. Mattress sutures, simple mass sutures and gauze packs may be effective in the initial control of bleeding, but it may create a dead space, hematoma and intrahepatic abscess or even necrosis of liver tissues with the development of sepsis ${ }^{6)}$. In the recent series, we employed direct suture or ligation of used silver clips (hemoclips) of the bleeding vessels, in which the lacerations were separated and enlarged to obtain the control of bleeding points. After hemostasis by this method, an omental pedicle was fashioned using the techniques of STONE $^{7}$. We applied this method to 6 patients with moderate or severe ruptures with good results.

Of the patients sustaining severe hepatic trauma with main vessels injuries, sutures of liver were used in only 2 patients and resectional debridement or liver resection were needed in $77.3 \%$. Elective hepatic resections were required for the patients in whom suture ligations were unsuccessful. Our 9 patients with severe injuries of the right hepatic lobe underwent right lobectomy with 2 deaths. The mortality of emergency hepatic resection was reported as 
$10 \%$ to $52 \%$ from several hospitals. ${ }^{1,89}$ In the recent series, we attempted to preserve viable liver tissues as far as possible. Therefore, hepatic resection was done in only one patient.

Our choice of surgical procedures for blunt hepatic trauma is shown in Table 9. Although lobectomy or resectional debridement are advocated as an operative procedure for massive injury, a conservative management for mild or moderate ruptures is still the most highly recommendable measure and must be caried out to the extent that the patient's condition will allow.

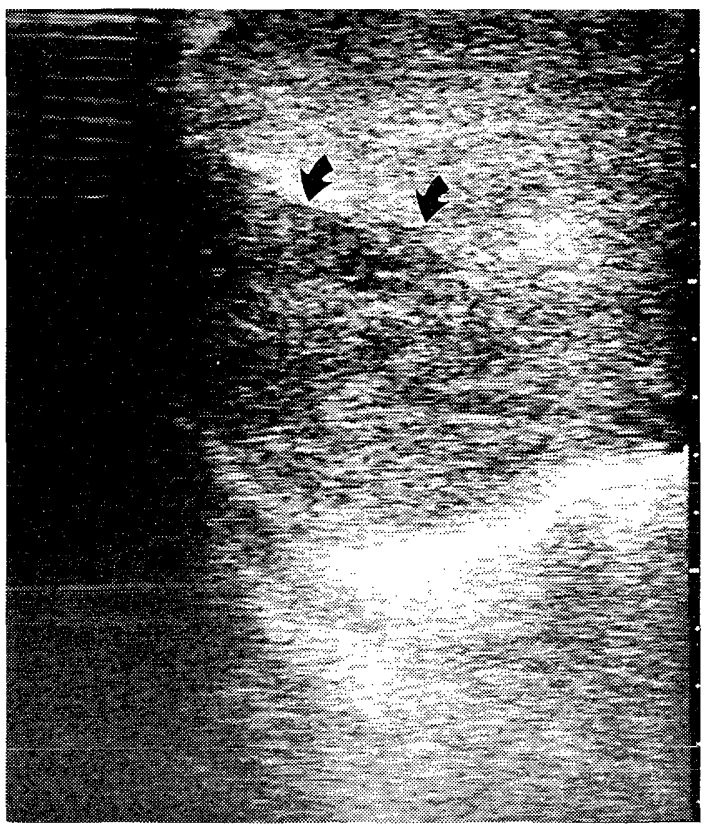

Fig. 1. US of 4 year-old boy sustained by traffic accident showing multiple lineal low density area in right lobe.
Table 9. Operative Management of Hepatic Rupture

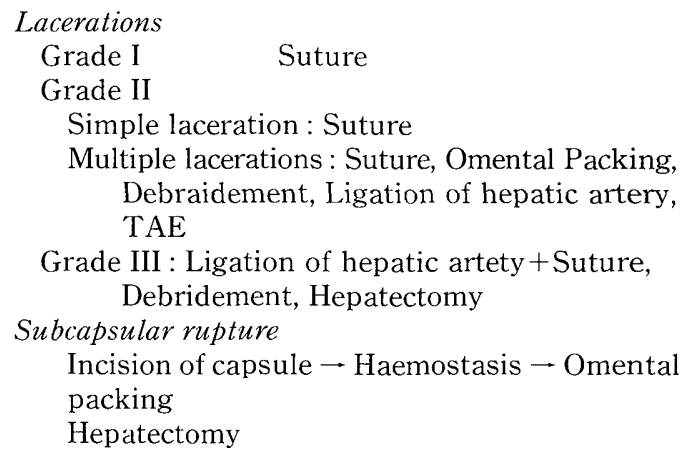

Multiple lacerations : Suture, Omental Packing, Debraidement, Ligation of hepatic artery, TAE

Grade III : Ligation of hepatic artety + Suture, Debridement, Hepatectomy

\section{Subcapsular rupture}

Incision of capsule $\rightarrow$ Haemostasis $\rightarrow$ Omental packing

Hepatectomy

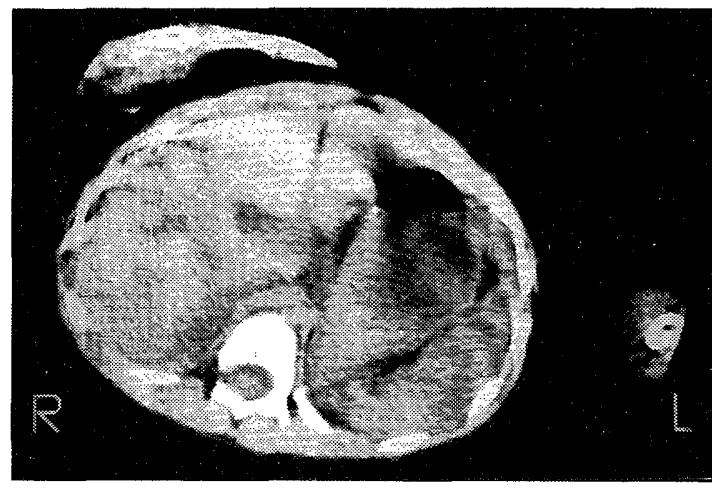

Fig. 2. CT imaging of same patient as Fig. 1 demonstrating multiple intraparenchymal rupture (transcapsular rupture, grade II).

\section{REFERENCES}

1) Defore, W. W., Mattox, K. L., Jordan, G. L., Beall, A. C.: Management of 1,590 consecutive cases of liver trauma. Arch surg. 111:493-497, 1976.

2) Raval, B., Lamki, N. : Computed tomography of the traumatized abdomen. Semminars in Ultrasoud, CT and MR. 6:109-118, 1985.

3) Moynihans, B.: Abdominal operation Vol 2. Saunders, Philaderphia. P. 231, 1926.

4) Donovan, A. J., Michaelian, M. J., Yellin, A. : Anatomical hepatic lobectomy in trauma to the liver. Surgery. 73: 833-847, 1973.

5) Guerra, J. J., Viamonte, M. : Diagnosis and therapy of liver trauma, Current role of radiology. RIR $10: 95-100,1985$.

6) Mays, E. T.: The hazards of suturing certain wounds of the liver. Surg. Gynecol. Obstet. 143 : 281-296, 1976. 
7) Stone, H. H., and Lamb, J. M.: Use of pedicled omentum as an autogenous pack for control of hemorrhage in major injuries of the liver. Surg. Gynecol. Obstet., 141 : 92-94, 1975.

8) Pachter, H. L., Spencer, F. C. : The management of complex hepatic trauma. Controversies In Surg II, P.241, 1983.

9) Moore, F.A., Moore, E. E., Seagraves, A. : Nonresectional management of major hepatic trauma. An evolving concept. Am. J. Surg. 150 : 725-731, 1985.

10) Shimoyama, T., Fukuda, Y., Shimizu, T., Ishikawa, H., Kawaguchi, A., et al. : Nonoperative managemment of blunt hepatic trauma. Acta Med. Nagasaki, 32 : 123-129, 1987.
11) Cheatman, J. E., Smith, E. J., Tunell, W.P., Elkins, R. R.: Nonoperative management of subcapsular hematoma of the liver. Am. J. surg. $140: 852-857,1980$.

12) Karp, M. P., Cooney, D. R., Pros, G. A., Newman, B. M., Iewett, T.C.: The nonoperative management of pediatric hepatic trauma. J. Pediat. surg. $18: 512-518,1983$.

13) Michael, B., Michael, P., Eric Tompson, Hugh J. Williams, Jr., Peter Mucha, Jr., and Duane M. Ilstorup: Nonoperative management of blunt hepatic trauma in adults. Surgery, 104:748-755, 1988. 